\title{
Evaluation of knowledge, attitude and practices in hand hygiene of students in biological sciences from Felix Houphouët-Boigny University of Cocody (Abidjan-Côte d'Ivoire)
} N'gbesso Jean-Paul N'GBESSO ${ }^{1 *}$, Nicaise Aya N'GUESSAN ${ }^{2}$, Alexis Loukou BROU ${ }^{3}$, Jean-Romaric ALLOKA ${ }^{4}$, Félix Kouamé N'DRI ${ }^{5}$, Guy Roger GNAZALE ${ }^{6}$

\footnotetext{
${ }^{1,2,4}$ Laboratory of Zoology and Animal Biology, Félix Houphouët-Boigny University, 22 B.P. 582, Abidjan 22, Côte d'Ivoire

${ }^{3}$ Lorougnon Guède University, Daloa, Côte d'Ivoire

${ }^{5,6}$ University Center for Research and Application in Remote Sensing, Félix Houphouët-Boigny University, Abidjan, Côte d'Ivoire
}

\begin{abstract}
The purpose of this paper is to identify risk factors, analyze and compare their effects on student hygiene behavior at Félix Houphouët-Boigny University. It is a descriptive and analytical cross-sectional study, initially covering 333 students in the second and third year of Training and Research Unit of Biosciences from University Félix Houphouët-Boigny enrolled during the university year in 2015-2016. A total of 318 out of 333 students Interviewed or $95.49 \%$ attending the toilets. The majority of the students questioned, 219 (65.76\%), had poor hand hygiene practices. There is a non-significant difference between hand hygiene practice and gender $(p$ =0.16). A staff of 325 students questioned out of 333 or 97.59\% denounced a lack of toilets. $95.49 \%$ of them are aware of the handwashing procedure. The toilets are also used by girls and boys. We note an insignificant difference between toilet use and sex $(p=0.76)$.
\end{abstract}

The correct practice of handwashing is not practiced by the students of Training and Research Unit of Biosciences; this was confirmed by direct observation. In the area of toilet surveys, lacks of hygiene equipment and inadequate toilets have been reported.

Understanding the challenges of hand hygiene practice in academic may help in the development of hand hygiene promotion strategies for the prevention of infections, especially those that are handled. The promotion of hand hygiene should start with health education.

Keywords-Hand, Hygiene, university, Abidjan, Côte d'Ivoire.

\section{INTRODUCTION}

Poor hygiene is a major concern in many low-income countries, especially those in sub-Saharan Africa (IFRCS, 2007; CSRS, 2013). This situation leads to the proliferation and spread of several germs responsible for pathologies (Racurt, C. et al., 2006; Adoubryn et al., 2005; Rasso et al., 2005; Mouchet et al., 1987; SOLIDARITE International, 2017). The hand represents the tool most often used by humanbeing and serves him to interact with his environment (Santé Canada, 2010). This environment is colonized by a varied flora. In contact and colonized by these germs, the hand constitutes a potential vector of these. Hence, hand hygiene is an essential element for the public health mission to reduce the transmission and the consequences of pathologies, especially man-made diseases. Optimal hand hygiene behavior will be considered the cornerstone of prevention (Red Cross Côte d'Ivoire, 2014; SOLIDARITE International, 2017; WHO, 2017a). Infectious diseases of parasitic, bacterial or viral origin are often the cause of high absenteeism among students. This often leads to a drop in their academic performance (Eau-vive, 2010; Diallo, 2015). Many of these infectious diseases are handled and their eradication requires hygienic behaviors, including handwashing (Delphine, 2008; SFHH, 2009). Investment in the water and sanitation sector produces considerable economic benefits. It is estimated that a dollar invested in these services would be a profit of \$ 4.3 (WHO, 2017a). Ebola haemorrhagic fever has plagued many countries neighboring Côte d'Ivoire in 2014 
(WHO, 2013). The man becomes contaminated when he comes into contact with the excretions of a man, an animal (bat, chimpanzee ...) sick or healthy carrier. As far as contamination between man is concerned, it is a horizontal or human-tohuman transmission. In this type of transmission, the disease spreads rapidly in high density populations. The promiscuity of the student population at the Félix Houphouët-Boigny University is worrying. In addition, it was found that the illustration poster of the handwashing procedure does not exist in our toilets. The aim of this study is to evaluate the hygiene practices of students studying animals (domestic and wild) in order to assist in the promotion of hand hygiene.

\section{MATERIAL AND METHODS}

\subsection{Material}

Three categories of materials were used in our study. These include the survey equipment, the toilet survey sheet and the hand-held observation record of hand hygiene practice.

\subsubsection{Survey equipment}

It is a questionnaire which covers the main themes concerning general hygiene: Knowledge of hand hygiene, knowledge of handwashing procedures and self-assessment of hygienic behavior. The questionnaire, to be easily accepted by the students surveyed, was reduced to the basic hygiene notions for everyday practice. It was subjected to the critical reading of students who were not part of the survey and was validated by a statistician of ENSEA (National School of Statistics and Applied Economics).

It consists of five parts:

The first part concerns the student himself: his name, level of study, nationality, age, sex, ethnicity, religion, and place of residence. The second part concerns the knowledge of hygiene at university. There are six questions in this section. The student is asked if he attends university toilets, whether there are mixed toilets, whether the toilets are cleaned regularly, what equipment and materials are available for hand washing: present a washbasin in the consultation room, type of soap used, use of hydro-alcoholic gel, wiping equipment, trash. The third part contains 21 questions on the knowledge of procedures. The expected answers are yes or no. They include hand washing, use of hand sanitizer, sneezing in public places and the general presence of bacteria. The fourth part deals with the self-assessment of student's hygienic behavior and the importance they attach to different hand hygiene behaviors.

Finally the fifth and last part includes seventeen questions on the cleaning of computer systems.

\subsubsection{Prospecting equipment}

To find out about the toilets at Training and Research Unit of Biosciences, we used a digital camera to take pictures, a muffler to prevent bad odors and a pair of disposable gloves for safety measures.

\subsubsection{Equipment for direct observation}

Direct observation of the practice of hand hygiene was carried out by means of a card containing the identification of the subject, observation time (Morning, Afternoon and evening), hand washing behavior (None Washing, rinsing hands and washing hands with soap) and hand washing time.

\subsection{Methods}

This study was carried out over the period from May 2016 to April 2017. It is not intended to judge students but to try to know their habits in order to make them aware of this topical issue and to inform them about the latest recommendations. The first part of the work was the development of a questionnaire, a toilet survey and a good hand hygiene record.

\subsubsection{Population and study site}

The study was carried out at Félix Houphouët-Boigny University in Cocody-Abidjan (Côte d'Ivoire) (Figure 1). Demography is growing. It is estimated at more than 60,000 students (UFHB, 2016). The study population for the survey is made up of 
students in the second and third year of Bachelor of Animal Biology for the academic year of 2015-2016 of Training and Research Unit of Biosciences.

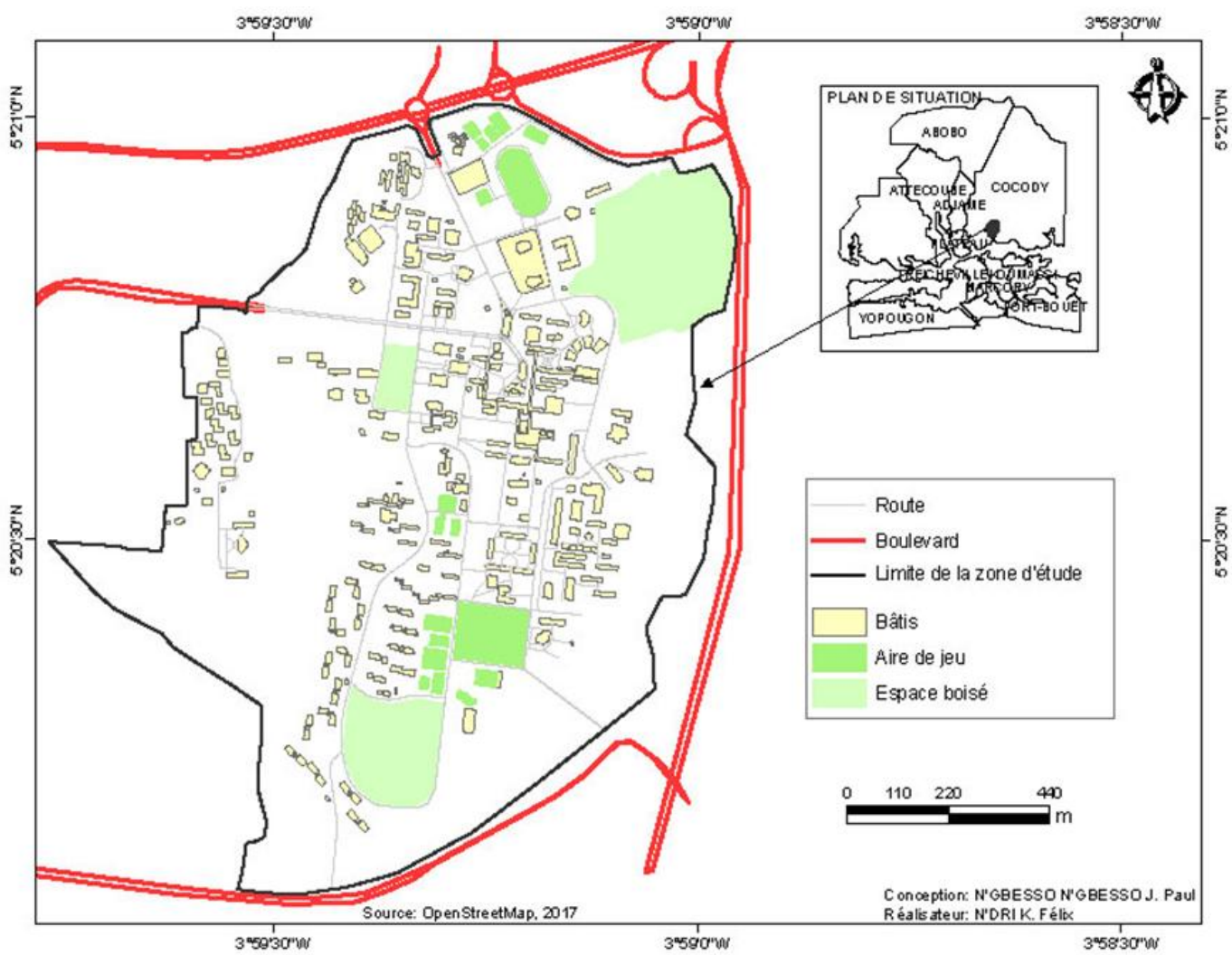

Figure 1. MAP OF STUDY SiTe

These are students specially for study animals. These students carry out by their specific practice gestures "at risk" from the point of view of transmission of germs on a daily basis. The observation to the good practice of the hygiene of the hands to concern the students of Training and Research Unit of Biosciences attending the toilets.

\subsubsection{Questionnaire survey}

A sample of all students in the second and third year of Training and Research Unit of Biosciences was interviewed as part of the survey. To do this, we listed the selected students. Then, based on their workforce, individual questionnaire forms were printed. After a presentation of the subject of the survey, a copy of the questionnaire was given to each student to fill it "anonymously", sometimes asking for help in understanding certain items. Participants are those who have given their verbal and written agreements (Figure 2). Then, the list and the number of corresponding cards were given to the delegate. The latter was responsible for handing over a questionnaire sheet to each volunteer student interested in the survey. The cards were received by the delegate after 48 hours, after a second clearance.

\subsubsection{Prospecting toilets}

The toilets were surveyed by direct observation in order to count the number of functional toilets, determine the available equipment and sanitation conditions. The surveys were carried out over a dozen months, from May 2016 to April 2017. They consisted of going around the toilets points for the students of the UFR Biosciences. At each point, the number of functional and non-functional toilets was counted. Then the existing hygienic material was identified.

\subsubsection{Direct observation of hand hygiene practice}

The observation was made discreetly by concealing the observations of hands washing behaviors. All observations were recorded using a standard coding form. The coding form consisted of the subject's ID, date, observation time, and hand washing behaviors. Washing behaviors were recorded in three categories: no washing (leaving the toilet without washing or rinsing hands), attempting to wash hands (wet hands without using soap) and washing hands with soap. Handwashing time 
was discreetly based on how many seconds the subjects' hands were placed under running water during washing, foaming and rinsing. Observation time was collected and the nominal time categories were formed at the end of the analysis.

\subsubsection{Data analysis}

The data were checked, coded and entered in Excel and analyzed using Software R version 3, 3, 3. For each respondent, the percentage of correct answers on a given theme allowed to classify it in the scoring grid developed from 0 to 100 . A score of positive responses less than or equal to 49, between 50 and 100 is considered respectively as Insufficient and acceptable. This score at the thematic level is reflected on each chapter according to the same principle.

For direct observation to good hand hygiene practice, the data were compiled and analyzed using Chi-square analysis. More specifically, Chi-square analysis was used to identify statistically significant differences in the demographic variables of the subjects, environmental variables in toilets and hand washing behaviors.

Data from the toilet survey to a good observation of hand hygiene practice and from the survey were captured in the Excel software. Then, the percentage of students who participated in the survey and the percentage of the affirmative responses of the survey questions were calculated. The rates obtained were used to assess the participation of students in the survey and to assess their hygienic practices.

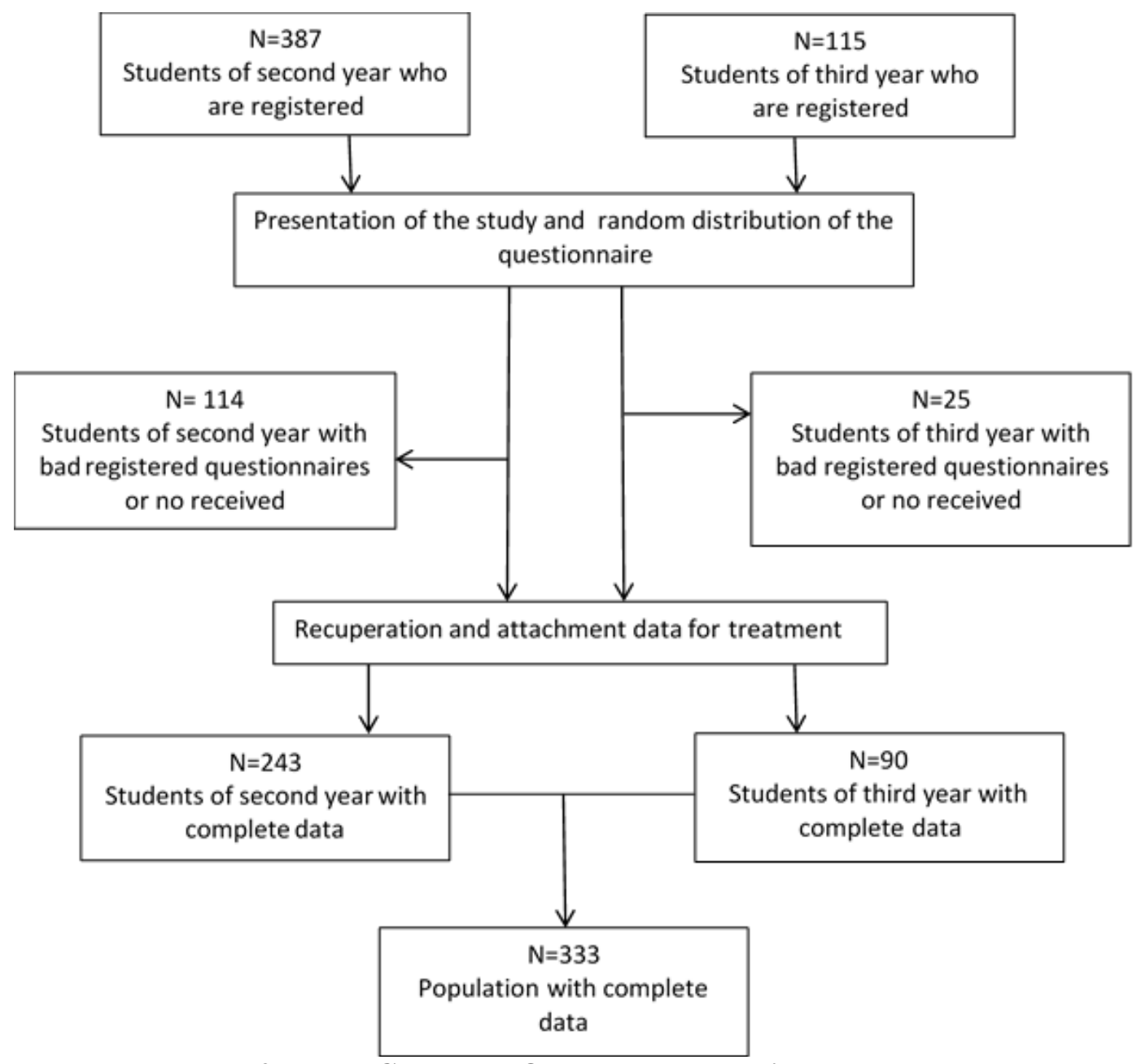

FiguRE 2. Flow CHART OF QUESTIONNEMENT'S METHODOLOGY

\section{RESUltS}

\subsection{Survey results}

\subsubsection{Sociodemographic characteristics of the population studied}

Three hundred and thirty-three (333) students were studied, including $243(72.97 \%)$ male and $90(29.02 \%)$ females [95\% CI $0.62-0.70]$. The average age is $24 \pm 6$ years. The study participation rate was $66.33 \%$ (Table 1 ). 


\subsubsection{Knowledge and Habit of Hand Hygiene of Students Questioned}

A total of 318 out of 333 students surveyed or $95.49 \%$ attended the toilets. The majority of students surveyed, $219(65.76 \%)$, had poor hand hygiene practices, compared to 114 (34.23\%) who had an acceptable hygiene practice (Figure 3). There is a non-significant difference between hand hygiene practice and gender $(\mathrm{p}=0.16)$.

\section{TABLE 1}

Distribution of PARTiCiPANTS BY Characteristics SoCiO-DEMOGRAPHiC

\begin{tabular}{|c|c|c|c|c|}
\hline \multicolumn{2}{|c|}{ Variables } & \multirow{2}{*}{$\begin{array}{c}\text { Frequencies } \\
243\end{array}$} & \multirow{2}{*}{$\frac{\text { Percentage \% }}{72.97}$} & \multirow{2}{*}{$\frac{95 \% \text { CI }}{[0.62-0.70]}$} \\
\hline C & Male & & & \\
\hline Gender & Female & 90 & 27.02 & {$[0.22-0.32]$} \\
\hline Total & & 333 & & \\
\hline \multirow{4}{*}{ Nationality } & Ivoirian & 326 & 97.89 & {$[0.95-0.99]$} \\
\hline & Burkinabe & 3 & 0.9 & {$[0.001-0.026]$} \\
\hline & Béninoise & 3 & 0.9 & {$[0.001-0.026]$} \\
\hline & Malienne & 1 & 0.3 & [7.602656e-05 -0.016] \\
\hline Total & & 333 & & \\
\hline \multirow{2}{*}{ Level of study } & Second year & 241 & 72.37 & {$[0.67-0.77]$} \\
\hline & Third year & 92 & 27.62 & {$[0.22-0.32]$} \\
\hline Total & & 333 & & \\
\hline \multirow{6}{*}{ Ethnicity } & Baoulé & 81 & 24.32 & {$[0.19-0.29]$} \\
\hline & Sénoufo & 40 & 12.01 & {$[0.08-0.15]$} \\
\hline & Agni & 31 & 9.30 & {$[0.06-0.12]$} \\
\hline & Malinké & 20 & 6 & [0.03-0.09] \\
\hline & Attié & 15 & 4.5 & {$[0.02-0.07]$} \\
\hline & Other & 146 & 43.84 & {$[0.38-0.49]$} \\
\hline Total & & 333 & & \\
\hline \multirow{4}{*}{ Religion } & Christian & 235 & 70.57 & {$[0.65-0.75]$} \\
\hline & Moslem & 71 & 21.32 & {$[0.17-0.26]$} \\
\hline & Animist & 1 & 0.3 & [7.602656e-05 -0.016] \\
\hline & None & 26 & 7.80 & {$[0.05-0.11]$} \\
\hline Total & & 333 & & \\
\hline
\end{tabular}

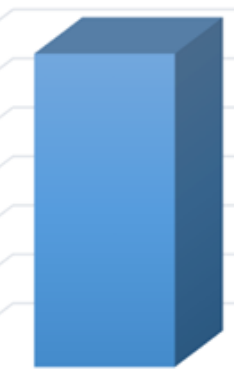

Bad hygiene

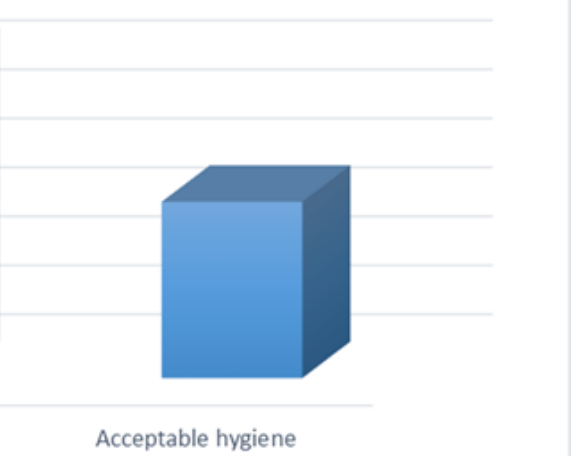

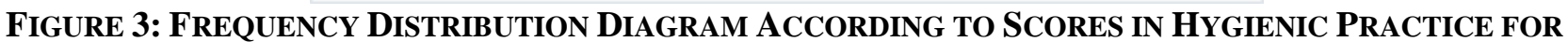
STUDENTS OF TRAINING AND RESEARCH UNIT OF BIOSCIENCES 


\section{TABLE 2}

\section{DisTRIBUTION OF FREQUENCY ACCORDING TO SCORES IN KNOWLEDGE OF STUDENTS OF TRAINING AND} RESEARCH UNIT OF BIOSCIENCES

\begin{tabular}{|c|c|c|c|}
\hline \multirow{2}{*}{ Thematic } & \multicolumn{3}{|c|}{ Score (\%) } \\
\cline { 2 - 4 } & $\mathbf{7 0 - 1 0 0}$ & $\mathbf{5 0 - 6 9}$ & $\leq \mathbf{4 9}$ \\
\hline Hands washing & $95(28.52 \%)$ & $207(62.16 \%)$ & $31(9.30 \%)$ \\
\hline Using hands desinfectant & $129(38.73 \%)$ & $133(39.93 \%)$ & $71(21.32 \%)$ \\
\hline Sneezing in public site & $254(76.27 \%)$ & $54(16 \%)$ & $25(7.50 \%)$ \\
\hline Presence of germs pathogenic & $317(95.19 \%)$ & $14(4.20 \%)$ & $2(0.6 \%)$ \\
\hline
\end{tabular}

At the level of the various themes, hand washing, the use of hand sanitizer, sneezing in public places and the presence of pathogenic germs, we note average knowledge in general of students (Table 2).

\subsection{Results of the prospecting of the different toilets of the students}

At the level of toilets surveys, a lack of hygiene equipment ( $\mathrm{PH}$, soap or disinfectant liquid ...) and inadequate toilets have been reported. The toilets are the main sites for hand washing of students.

At the circumference of the Training and Research Unit of Biosciences, we counted nine (9) toilets area.

Of the 9 student washrooms area, five (5) or $55.55 \%$ were accessible at the start of the survey to stabilize at four (4) toilets area by the end of the survey $(44.44 \%)$. We note that there were 16 functional toilets on a total of 26 toilets or $61.53 \%$, for all students of Training and Research Unit of Biosciences. In addition, there is no hygienic material (Figure 4)

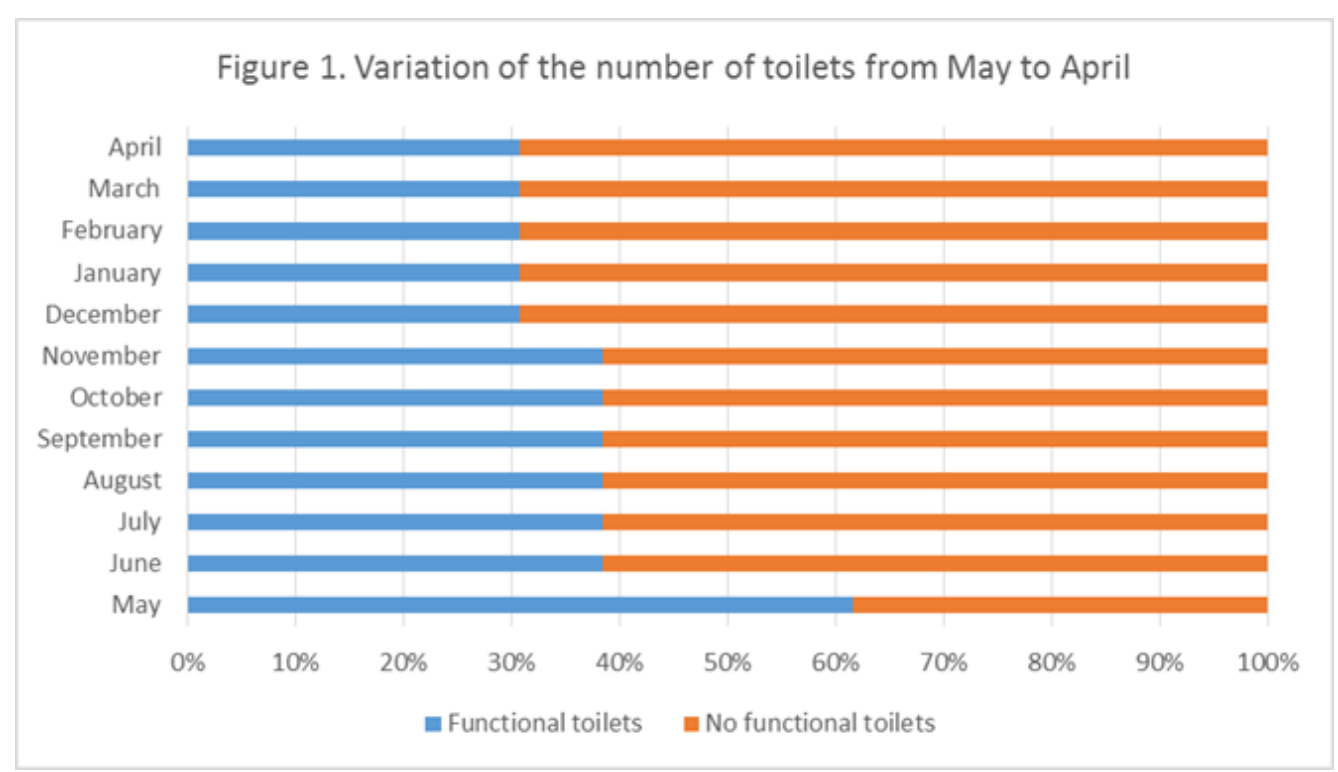

\section{Figure 4: VARIATION OF FUnCTIONAL AND NON-FunCTIONAL TOILETS BY MONTH}

\subsection{Direct observation of hand washing at toilet points}

Direct observation on the ground revealed that men were more likely to use toilets than women, with a proportion of $92.86 \%$ compared to $7.14 \%$ (Table 3).

Chi-square analysis revealed statistically significant differences in handwashing behavior between length of hands washing timeand sex, and hand washing behavior and sex (Table 3). For example, about $96.10 \%$ of students do not wash their hands, compared to $3.9 \%$ of students. Male subjects frequent toilets at any time more than female subjects. The gender difference was confirmed with women using soap and engaging in proper handwashing behavior significantly

Conventional handwashing with soap and water is not practiced by any student and the time of passage of the under-running water during the washing does not exceed 15 seconds. 


\section{TABLE 3}

ChI-SQuare TeSt: COMPARISON OF HAND WASh BeHAVIOR ACCORDING TO SEX ( $\mathrm{N}=6$ 16)

\begin{tabular}{|c|c|c|c|c|}
\hline Variable & \multicolumn{2}{|c|}{ Sex } & $\mathbf{X}^{2}$ & \\
& $\begin{array}{c}\text { Male } \\
92.86 \% \\
(\mathrm{n}=572)\end{array}$ & $\begin{array}{c}\text { Female } \\
7.14 \% \\
(\mathrm{n}=44)\end{array}$ & & \\
\hline Observation time & $\%$ & $\%$ & 1.328 & $\mathrm{p}=0.5146$ \\
\hline Morning & 93.18 & 6.82 & & \\
\hline After-noon & 90.48 & 9.52 & & $\mathrm{p}<0.05$ \\
\hline Evening & 95.24 & 4.76 & & \\
\hline Washing behavior & & & 35.066 & \\
\hline No washing & 96.10 & 3.90 & & $\mathrm{p}<0.05$ \\
\hline Rinsing & 80.47 & 19.53 & & \\
\hline Washing hands with soap & 0 & 0 & & \\
\hline Length of hands washing time & & & 52.569 & \\
\hline 0 seconds & 96.10 & 3.90 & & \\
\hline $1-8$ second(s) & 83.05 & 16.95 & & \\
\hline 9-14 seconds & 50 & 50 & & \\
\hline 15 seconds or longer & 0 & 0 & & \\
\hline
\end{tabular}

\section{DISCUSSION}

This study revealed that there are only four (4) toilets areas accessible to students out of the nine (9) that exist in the academic space of Training and Research Unit of Biosciences. At these four points, only sixteen (16) toilets are functional. When reporting the number of registered students (1498 individuals) out of sixteen (16) available toilets, we note a toilet for eighty-four (94) individuals.

This increases the number of people defecating in the open air. This has been demonstrated by WHO as this practice evolves as the number of people concerned increases (WHO, 2017b). It is then necessary to rehabilitate the points of the flawed toilets in order to put a larger number of toilets at the disposal of the students and to carry out a health education for a change of behavior.

In this momentum, we will be able to meet the objective of sustainable development, which stipulates that by 2030, ensure equitable access to sanitation and hygiene services for all and with a focus on the needs of women, girls and vulnerable people (UNICEF, 2017).

The exponential decrease of the toilets undoubtedly demonizes a very strong attendance of the university toilets. Heavy attendance may make these toilets at risk of infection. It should be noted that all toilets are mixed. This demonstrates the importance of interventions in the water, sanitation and hygiene (WASH) sector that can help prevent a wide range of diseases (diarrhea...) (WHO, 2017b). According to the WASH (Water Sanitation and Hygiene) charter, which stipulates that a toilet for every twenty (20) male and one toilet for fifteen (15) female individuals is required (Red Cross Côte d'Ivoire, 2014). In this context, it would be possible to ensure hygiene and sanitation favorable to all students.

Moreover, the toilets are only regularly washed with soap and rarely with bleach. This may be to avoid waiting for some students to defecate and urinate in the open air.

In general, the toilets were clean during our surveys despite their high attendance. It may be because they were cleaned 3 times a day that they looked clean. But the fact that they are often washed with soap and rarely with bleach demonstrates that they are not completely disinfected. Because soap alone is not enough to kill the majority of germs. Thus, relieving oneself in toilets could be a risk (WHO, 2017c). There is a greater risk of leaving the toilet because there is no toilet paper or soap to wash the hands after relieving so the students do not wash their hands with water and soap. We believe that even if $93.96 \%$ of the students know that washing their hands with water alone is useless, they can not do otherwise because the accessories (toilet paper, soaps, disinfectants ...) do not exist toilet. As $79.33 \%$ of respondents know that disinfectants are effective in cleansing hands may be that they use it.

These results demonstrate that the risk of infection in the heads of faucets, handles of toilet doors is not negligible in the study area because water alone is used to wash hands after the need. Thus, preventive measures such as hand washing with 
soap and hand sanitizing recommended by WHO (WHO, 2010) are not practiced by students at Training and Research Unit of Biosciences.

Hand washing is the most effective way to reduce the spread of infectious diseases according to CDC (CDC, 2012; Mead et al., 1999). Our study provided detailed information on the duration and in which environments different groups engaged in various handwashing behaviors. Our study recognizes the importance of environmental factors that promote proper hand washing behaviors. To our knowledge, our study was one of the first studies to focus on hand washing behaviors and wash time while incorporating environmental factors and observation time

The study revealed that none was washing hands with soap and water. This is an important discovery because a high percentage of people do not wash properly and signs that include messages highlighting proper hand washing or reminders to use soap can increase compliance. It seems that this type of explicit recall may be particularly useful in men's toilets (Larson et al., 1997; Larson, 1991).

The study of the effect of time of day on the behavior of hand washing showed that hand washing generally decreased during the evening. The most important results of our research concern the distinction between hand washing behaviors and hand length were washed. Specifically, no individual in the sample approached the recommended hand washing time.

\section{CONCLUSION}

We note that the students interviewed know the hygienic practices of handwashing. But they can not apply it entirely because they can only wash their hands with water alone because hand soaps and disinfectants do not exist in the toilet. Thus, preventive measures are not practiced by students at Training and Research Unit of Biosciences.

Understanding the challenges of hand hygiene practice in academia may help in the development of hand hygiene promotion strategies for the prevention of infections, especially those that are handled.

\section{LIMITS OF THE STUDY}

It should be noted that the observations took place only in an academic environment in a Training and Research Unit (Department of Chemistry Animal Biology). It is therefore necessary to take care to generalize the results throughout the university. It should be recognized, however, that even an apparent discreet observation may influence hand washing behaviors because the simple presence of others in a toilet may lead to increased compliance (Bittner et al., 2002; Drankiewicz, 2003; Edwards et al., 2002; Nalbone, 2005). It would be good to include in the future studies the drying act because studies have shown that transfer of microorganisms is more likely to occur from moist than dry skin (Mackintosh, 1984; Merry et al., 2001; Patrick, 1997).

\section{ACKNOWLEDGEMENT}

Our thanks go to the President and the Vice-President in charge of research at the Félix Houphouët-Boigny University in Cocody for authorization to carry out the study. We also thank the Director of the Laboratory of Zoology and Animal Biology and all the students who participated in the study.

\section{REFERENCES}

[1] Adoubryn K. D., Ouhon J., Yapo C. G., Assoumou E. Y., Ago K. M., et Assoumou A. (2005). Profil épidemiologique des schistosomoses chez les enfants d'âge scolaire dans la region de l'Agneby (Sud-est de la Cote d'Ivoire). Bulletin de la pathologie Exotique, Vol. 99, $\mathrm{N}^{\circ} 1$, pp $28-31$.

[2] Bittner, M., Rich, E., Turner, P. \& Arnold, W. (2002). Limited impact of sustained on-the-job feedback. Infection Control Hospital Epidemiology, 23 (3), pp 120-126

[3] CSRS (2013). Swiss Center for Scientific ResearchAnnual Activity Report 2012 - 2013. 346p.

[4] CDC (2012). Centers for Disease Control and Prevention-Hand washing: Clean hands save lives. Retrieved from http://www.cdc.gov/ handwashing.

[5] Drankiewicz, D., and Dundes, L. (2003). Hand washing among female college students. American Journal of Infection Control, 31 (2), pp 67-71.

[6] Delphine SALABERT wife Dubar (2008). Ph.D. thesis in general medicine: State of the art in a commune of high breasts University Pierre and Marie Curie, 122p.

[7] Diallo A. C., (2015). Evaluation of Hygienic Handwashing Practices, Microbiological Sampling and Analyzes: Student and Staff Case Studies at the Université de Moncton, Moncton Campus. Master of Science in Nutrition and Food, Université de Moncton, Canada, 118p. 
[8] Eau vive (2010). For better dissemination of sanitation facilities in Sahelian rural areas 80 concrete proposals - March 2010 Synthesis of the study.

[9] Feachem R.G., J. Briscoe and M. Mujibur Rahaman, (1987). Health Effects Assessment: Water Supply, Sanitation and Hygiene. UNICEF, ICDDR_B, IDRC (International Development Research Center), Ottawa, Canada, 86p.

[10] FRCS (2007). International Federation of Red Cross and Red Crescent Societies, the International Federation of Software Tools for Long-term Water and Sanitation Programming 52p.

[11] Larson, E., Bryan, J., Adler, L.M., \& Blane, C. (1997). A multifaceted approach to changing hand washing behavior. American Journal of Infection Control, 25 (1), pp 3-10.

[12] Larson, E., McGeer, A., \& Quiaishi, Z. (1991). Effect of an automated sink on hand washing practices and attitudes in high-risk units. Infection Control Hospital Epidemiology, 12 (7), pp 422-428.

[13] Mouchet J.(1991). Water-related diseases in Afro-tropical regions, Multidisciplinary Colloquium Geography-Medicine on water and health in tropical Africa, Limoges, October, PUPLIM, pp. 47-59.

[14] Mead, P.S., Slutsker, L., Dietz, V., McCaig, L.F., Bresee, J.S., Shapiro, C., Griffin, P.M., \& Tauxe, R.V. Food related death and illness in the United States. Emerging Infectious Diseases, 5 (5), pp 607-625.

[15] Mackintosh, C., \& Hoffman, P. (1984). An extended model for transfer of microorganisms via the hands; Differences between organisms and the effect of alcohol disinfection. Journal of Hygiene, 92 (3), pp 345-355.

[16] Merry, A., Millder, E., Findon, G., Webster, C., and Neff, S. (2001). Touch contamination levels during anaesthetic procedures and their relationship to hygiene procedures: A clinical audit. British Journal of Anesthesia, 87 (2), pp 291-294.

[17] Nalbone, P., Lee, K., Suroviak, A., and Lannon, J. (2005). The effects of social norms on male hygiene. Individual Differences Research, 3 (3), pp 171-176.

[18] Patrick, D., Miller, T., \& Findon, G. (1997). Residual moisture determines the level of touch-contact associated with hand washing. Epidemiology and Infection, 119 (3), pp 319-325.

[19] Racurt C P, P Brewer and I. Verdier R. (2006). Human Cryptosporidiosis and species at issue in Haiti [Review] // Tropical Medicine International Health. - pp. 925-34.

[20] Rasso G, J and Utzing Silue K. D. (2005). Disparities in parasitic infection, health care Perceived ill heo Among Poorer and less rural schoolchildren of Ivory Coast [Review] // International Tropical Medicine Health. - 10. - pp. 42-47.

[21] REPUBLIC OF KENYA, (2004) Information and Communication Technology. Strategy discussion paper. Ministry of Education, Science and Technology - TIC Unit

[22] Red Cross Côte d'Ivoire (2014) training of volunteers in the techniques of construction of latrines in sanplat dalle of promotion of hygiene and of treatment of the water / service wash / CRF-CRCI modified in September 2012 by GUEHI Aimé Magloire technician WASH

[23] Santé Canada (2010). Votre santé et vous: Lavage des mains et ses biens faits, 3p

[24] SFHH (2009). Hand Hygiene Recommendation. Hygiene. ISSN 1249-0075 Volume 17 (3): pp 141-240.

[25] SOLIDARITE International (2017). http://www.solidarites.org/fr/depuis-1980/mandathumanitaire/gclid=CjwKEAjwhrzLBRC35F9Ssh0FASJAD5obJ1cGoA84vy0ETYwMxFASJAD5obJ1cGoA8vYOETYwMxMxFF accessed on 31 February 2017

[26] UFHB (2016). Université Félix Houphouët-Boigny : www.univ-fhb.edu.ci, accessed 03 janvier 2016.

[27] UNICEF (2017). https: //www.unicef.org/english/wash/3942_43108.html accessed 17022017.

[28] WHO (2010). Hand Hygiene: Technical Reference Manual For health professionals, trainers and observers of hand hygiene practices; World Health Organization 2010; Available at http://www.who.int/gpsc/5may/tools/training_education/gpsc_hhtool_TRM_2010_40en.pdf. 2010. Available to 10-10-2010.

[29] WHO (2013). Diarrheal diseases. Fact Sheet No. 330 April 2013, 3p. WWW. Who. Int / mediacentre / factsheetsfs 330 / fr /, accessed 04 November 2014

[30] WHO (2017a).http://www.who.int/water_sanitation_health/monitoring/economics/en/accessed 17 September 2017.

[31] WHO (2017b). Water-relateddiseases http://www.who.int/water_sanitation_health/diseases-risks/diseases/en/ Accessed 20032017.

[32] WHO (2017c) Diseases and risks related to poor sanitation http://www.who.int/water_sanitation_health/diseases-risks/en/ accessed 20032017. 